\title{
Exploratory Factor Analysis of the Student Adaptation to College Questionnaire Short Version in a Sample of Chilean University Students
}

\author{
Yaranay López-Angulo ${ }^{1,2, *}$, Rubia Cobo-Rendón ${ }^{3}$, Fabiola Saéz-Delgado ${ }^{4}$, Alejandro Díaz Mujica² \\ ${ }^{1}$ Psychology Department, Faculty of Social Sciences and Communications, Universidad Santo Tomás, Concepción, Chile \\ ${ }^{2}$ Psychology Department, Faculty of Social Sciences, Universidad de Concepción, Concepción, Chile \\ ${ }^{3}$ Faculty of Psychology, Universidad San Sebastián, Concepción, Chile \\ ${ }^{4}$ Department of Fundamentals of Pedagogy, Faculty of Education, Universidad Catolica de la Santisima Concepcion, Concepcion, Chile
}

Received June 1, 2020; Revised December 9, 2020; Accepted January 25, 2021

\section{Cite This Paper in the following Citation Styles}

(a): [1] Yaranay López-Angulo, Rubia Cobo-Rendón, Fabiola Saéz-Delgado, Alejandro Díaz Mujica , "Exploratory Factor Analysis of the Student Adaptation to College Questionnaire Short Version in a Sample of Chilean University Students," Universal Journal of Educational Research, Vol. 9, No. 4, pp. 813 - 818, 2021. DOI: 10.13189/ujer.2021.090414.

(b): Yaranay López-Angulo, Rubia Cobo-Rendón, Fabiola Saéz-Delgado, Alejandro Díaz Mujica (2021). Exploratory Factor Analysis of the Student Adaptation to College Questionnaire Short Version in a Sample of Chilean University Students. Universal Journal of Educational Research, 9(4), 813 - 818. DOI: 10.13189/ujer.2021.090414.

Copyright@2021 by authors, all rights reserved. Authors agree that this article remains permanently open access under the terms of the Creative Commons Attribution License 4.0 International License

\begin{abstract}
Background: The problem of studies abandonment greatly affects university students at different levels of training. The permanence in a university career depends on the adaptation skills of the students to the new educational context, which is why, its measurement is relevant for the identification and accompaniment of at-risk students. The objective of this work was to evaluate the internal structure of the Student Adaptation to College Questionnaire [SACQ] short version in a sample of Chilean university students. Method: A total of 249 first-year students from a southern Chilean university participated. The average age of the participants was 19.11 years [SD = 5.29]. The SACQ short version was used with 47 items distributed in four dimensions: academic, social, emotional and institutional adjustments. Results: After a new organization of the items by means of an exploratory factor analysis a four-factor structure was obtained. Adequate correlations were identified between the items and the dimensions of the questionnaire. Conclusions: The new version of the SACQ is a measure with adequate internal validity to measure the adaptation of the university students in the context of Higher Education in Chile, however, it is recommended to make a confirmatory factor analysis prior to its use.
\end{abstract}

Keywords Adaptation to College, University Students, Exploratory Factor Analysis

\section{Introduction}

The transition from one to another academic stage is an important aspect in the lives of students. During this period, a transformation process is presented in the way in which young people learn and relate within the new academic environment [1]. Adjustment to university life has been defined as the general process of coping with the motivation, execution and performance requirements of the characteristics of the university experience [2, 3]. It refers to all motivational, behavioral and emotional processes that the students unfold to face the daily demands of the university experience.

Research on adjustment to university life is important since the experiences of students (especially during the first year) have an impact on the desire for university maintenance or abandonment [4], being a reflection of success or failure of the students in the incorporation of the new values, norms and behaviors of the university 
academic community [5]. Measuring the adjustment to university life allows to effectively alert teachers and counselors about the students who are more likely to leave the institution in the early academic years [6, 7]. It has been argued that this concept could represent a type of "missing link" between the theoretical models of Bean [8], Pascarella [9] and Tinto [10], which focus mainly on retention and graduation results [4].

In the case of university students in Chile, the problem of abandonment is an issue that stands out in both the universities and the country's public policies [11], since nearly the $30 \%$ fail to graduate [12].

Adapting to university life requires various skills for managing multiple challenges originating in the university [13]. Four dimensions of students' adjustment have been proposed: academic, personal, social and institutional [3]. Academic adjustment refers to the success of students in facing the diverse educational demands of the university experience [3, 4, 14]. It includes the way in which students deal with educational demands, such as motivation to complete the academic requirements and the effort and satisfaction with the environment [7]. Social adjustment relates to the students' success in facing the interpersonal-social demands which are inherent to university life [3, 7]. It is linked to the way in which students are socially integrated at the university, including their participation in campus activities and their establishment of new interpersonal relationships. Weak social adjustment is associated with experiencing feelings of loneliness [4, 14].

The personal-emotional adjustment focuses on the psychological state of the students during the process of adaptation to university and the degree to which they are experiencing general discomfort $[3,7,14]$. The lack of personal adjustment is characterized by the presence of psychological anguish associated with the adaptation process. Institutional adjustment accounts for the students' commitment to educational-institutional objectives, their attachment to the institution and the quality of the relationship between the students and the educational institution [3].

At the empirical level, a significant amount of research that considers the adaptation of university students has been developed. A meta-analysis reports that academic adjustment shows weak relations with variables such as gender, age, socioeconomic status, and admission scores [4]. Adjustment is a variable that correlates with high self-efficacy beliefs $[15,16]$, with the perception of social support [4, 17], and high academic performance [18, 19]. It has been identified as a protector of mental health, decreasing depressive symptoms in students in the early academic years [20].

Considering the importance of this variable, several instruments have been designed for its measurement. One of the most widely used has been the SACQ, which was designed to assess how students adjust to higher education
[3]. It has been widely used in North America and it is considered the most important instrument to measure this construct [21]. It is a useful instrument to identify possible abandonments from university and it measures the general adjustment by means of the sum of its dimensions [6].

The 67 items presented in the original version were grouped into the 4 adjustment factors previously described: academic, social, emotional and institutional [3, 22]. Validation studies in university students from other countries such as Spain and the Netherlands maintain the 4-factor structure proposed in the original version [21, 23]. However, the literature presents other psychometric validation works where difficulties are described to test the fit of the model with four factors. Thus, different numbers of factors for the SACQ are proposed, such as 6 factors for validation in French students [24]. Difficulties have also been found regarding the relevance of the items for each factor, being the most important weaknesses of such a questionnaire [21, 25-27].

The original version of the SACQ questionnaire presents adequate reliability indices $[\alpha=.92$ to $\alpha=.95$ for the full scale and $\alpha>.77$ for the dimensions]. This result has been maintained in the responses of student samples from countries such as the France from $\alpha=.73$ to $\alpha=.91$ [24], China from $\alpha=.64$ to .75 [28], Spain $\alpha>.84$ [21] and Romania from $\alpha=.79$ to .94 [29].

In 2012, the adaptation in Spanish of the SACQ was presented [21], in this study an adapted version of the scale was applied to a sample of 300 first-year university students. After the statistical analysis of the original 63 items on the scale, the authors reported an adequate fit to a short version of 47 items, based on the model proposed by Baker and Siryk. Due to the importance and need for valid measures that allow evaluating the students' adaptation process to university and detecting possible cases at risk of abandonment, this paper aims to assess the internal validity of the SACQ short version in a sample of Chilean first-year university students.

\section{Method}

The present study corresponds to an instrumental non-experimental investigation [30], with the purpose of adapting and evaluating the internal structure of the SACQ. In this direction, the exploratory factor structure of the SACQ was analyzed in a sample of chilean university students.

\subsection{Participants}

The participants in this study were 249 first-year students belonging to a traditional university in Chile. The mean age was 19.11 years with a standard deviation of 5.29. Table 1 shows the distribution by career and sex. 
Table 1. Distribution of students per career and sex

\begin{tabular}{ccccc}
\hline & \multicolumn{3}{c}{ Gender } & Total per \\
Career & Male & Female & $\begin{array}{c}\text { No } \\
\text { answered }\end{array}$ & \\
\cline { 2 - 4 } & 29 & 64 & 1 & 94 \\
\hline Psychology & 12 & 65 & 0 & 77 \\
Obstetrics & 39 & 39 & 0 & 78 \\
$\begin{array}{c}\text { Chemistry and } \\
\text { Pharmacy }\end{array}$ & 80 & 168 & 1 & 249 \\
\hline Total per gender & & &
\end{tabular}

\subsection{Instruments}

The SACQ short Spanish version proposed by [21] was used in the present study. This version is made up of 47 items, distributed in 4 dimensions that focus on different aspects of the process of adaptation to university training (academic, social, personal-emotional and institutional adjustments). The response scale was modified from 9 to 7 response options ( $1=$ strongly disagree to $7=$ strongly agree). This proposal presented adequate model fit indices and adequate reliability indices in each of its dimensions, academic $\alpha=.90$; institutional $\alpha=.84$; social $\alpha=.85$ and emotional $\alpha=.89$ [21].

\subsection{Procedure}

The instrument was applied in the classroom with a printed booklet during the 2018-2019 academic year once the authorization was released from the Ethics Committee of the participating university, deans and heads of each career. Students were asked to sign an informed consent. For the analysis of the data from the first study, an Exploratory Factor Analysis (EFA) was carried out with extraction of main axes. The feasibility of the analysis was evaluated with the Bartlett sphericity test and the Kaiser Meyer - Olkin index (KMO). The structure was analyzed with the eigenvalues (Eigen), the Cattell sedimentation graph and the factor loads. The criterion proposed by Field [31] was used, who established that the factor loads in this type of analysis must be equal to or greater than .40. The structure was studied with the Varimax rotations, forcing the distribution of the items in four factors.

\section{Results}

\subsection{Exploratory Factor Analysis of the SACQ in Chilean University Students}

Exploratory factor analysis of the SACQ short version was carried out in Chilean university students. Initially, the Kayser-Meyer-Olkin (KMO) adequacy measure was identified as .823, the Bartlett sphericity test was significant $(\mathrm{p}<.001)$, confirming the possibility of performing the exploratory factor analysis. The results obtained report that the four indicated factors explain the $45.140 \%$ of the variance, a result that is confirmed in the sedimentation graph (see Fig. 1).

The analysis of the factorial weights of the items allowed identifying items that did not load any factor, which presented loads less than .40 or loaded different dimensions from the initial version. Specifically, item S42 belonging to the dimension of social adjustment: "I do not feel comfortable with certain people in the Career". It was eliminated because it did not load any factor. Seven items presented lower loads than what was theoretically established. From the academic adjustment dimension 3 items were identified (A52, A27, A13) and from the social adjustment dimension the remaining four items were found (S30, S8, S46, S57). In total, 8 items were removed from the initial version, leaving a total of 39. The distribution of the items per factor turned out to be similar, in Table 2 the loads of each item per factor are reported.

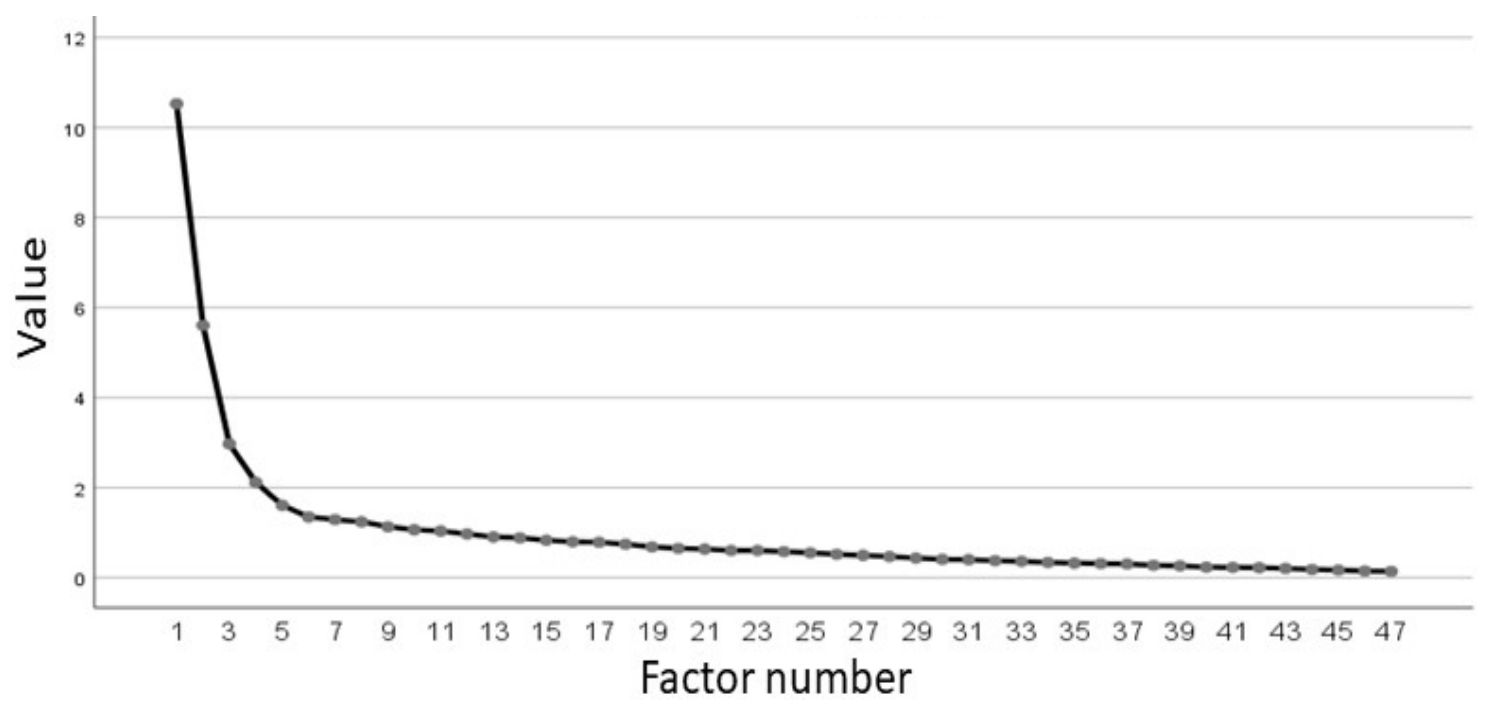

Figure 1. Sedimentation graph Cattell 
Table 2. Item loads per factor

\begin{tabular}{|c|c|c|c|c|}
\hline \multirow{2}{*}{ Item description } & \multicolumn{4}{|c|}{ Factors } \\
\hline & 1 & 2 & 3 & 4 \\
\hline P7. I have experienced sadness and quite a few mood swings lately & .732 & & & \\
\hline P20. I am not able to control my emotions lately & .715 & & & \\
\hline P64. I find it difficult to cope with the stress that university causes me & .714 & & & \\
\hline P11. I feel tired most of the time lately & .679 & & & \\
\hline A29. I don't feel very motivated to study lately & .645 & & & \\
\hline A28. I have headaches lately & .639 & & & \\
\hline P45. I often feel confused & .626 & & & \\
\hline P2. I've been feeling nervous lately & .620 & & & \\
\hline P12. I find it difficult to be alone and have so many responsibilities & .608 & & & \\
\hline P40. I don't sleep well lately & .604 & & & \\
\hline P55. I feel good lately & -.590 & & & \\
\hline P38. I get mad very easily lately & .589 & & & \\
\hline A21. I think I am not able to do everything that is required of me & .586 & & & \\
\hline A41. I'm not doing it well enough because of the amount of work I do & .576 & & & \\
\hline P31. I've been thinking about asking for psychological help lately & .519 & & & \\
\hline S63. I have good friends and acquaintances in the Career to tell them about any problem & & .683 & & \\
\hline S9. I'm adjusting well to university & & .664 & & \\
\hline S4. I am meeting people and making friends at the university & & .663 & & \\
\hline S1. I think I fit in well at the university & & .653 & & \\
\hline S37. I think I have enough social skills to integrate well to the university life & & -.595 & & \\
\hline S65. I am satisfied with my life at the university & & .508 & & \\
\hline S18. I have close personal relationships at the university & & .502 & & \\
\hline S51. I have felt very lonely in the Career lately & & -.455 & & \\
\hline I60. I'm thinking of leaving the university definitively & & & .705 & \\
\hline I47. I hope to finish my studies in this faculty & & & -.674 & \\
\hline I59. I'm thinking of moving to another faculty & & & .634 & \\
\hline I15. I am satisfied with my decision to go to college & & & -.608 & \\
\hline I34. I wish I was in another university or college faculty & & & .600 & \\
\hline A5. I know why I am in college and what I want to get out of it & & & -.557 & \\
\hline A58. Most of the things that I am interested in are not related to what I do in the Career & & & .524 & \\
\hline I61. I am seriously considering taking time off from college and continuing later & & & .501 & \\
\hline A19. My academic goals are well defined & & & -.500 & \\
\hline A32. I doubt the value that a university career can have & & & .471 & \\
\hline A54. I am satisfied with the subjects of this course & & & & .765 \\
\hline A43. I am satisfied with the quality of the subjects I have & & & & .695 \\
\hline A36. I am satisfied with the number and variety of subjects I have & & & & .666 \\
\hline A62. I am very satisfied with the teachers that I have this course & & & & .603 \\
\hline A50. I like the work I do in the subjects & & & & .428 \\
\hline S30. I am satisfied with the social activities offered by the university & & & & .365 \\
\hline A27. I like to do the term papers & & & & .337 \\
\hline S57. In short, I would rather be at home than here & .329 & & & \\
\hline A52. I have a hard time getting homework scheduled & .315 & & & \\
\hline A13. I am satisfied with the pace at which I am working & & .381 & & \\
\hline S8. I am very involved in the university life & & .374 & & \\
\hline S46. I am satisfied with my participation in the social activities offered by the university & & .374 & & \\
\hline A44. I am attending classes regularly & & & -.306 & \\
\hline S42. I am not comfortable with certain people in the Career & & & & \\
\hline
\end{tabular}

Note: Extraction method: factorization of main axes; Rotation method: Varimax with Kaiser normalization; The rotation has converged in 5 iterations.

Factor 1 corresponds to the set of items in the personal-emotional adjustment dimension (items P7, P20, P64, P11, A29, P28, P45, P2, P12, P40, P55, P38, A21, A41, P31). These 15 items refer to the psychological processes related to the adaptation process difficulties (anxiety, sadness, anger and tiredness), beliefs of inability to cope with the demands of the university life and the desire to seek psychological help. Three items from the dimension of academic adjustment were included within this very factor (A29 " I don't feel very motivated to study lately "; A21 "I think I am not able to do everything that is required of me"; A41; "I’m not it doing well enough 
because of the amount of work I do").

Factor 2 corresponds to the dimension of social adjustment (items: S63, S9, S4, S1, S37, S65, S18, S57). This dimension was constituted by 8 social adjustment items from the original version. The set of items in this dimension refers to the possibility that the university offers for the development of social skills: meeting people, establishing friendship and making friends; as well as the perception of adaptation: comfort and satisfaction for the social life of the university. In this version, item S57 ("I have felt very lonely in the Career lately") presented a negative charge as expected conceptually for this dimension. Item S37 ("I think I have enough social skills to integrate well to the university life") presented a negative charge, a result that was not expected for this dimension.

Factor 3 refers to the set of items belonging to the institutional adjustment dimension (items: I60, I47, I59, I15, I34, A5, A58, I61, A19, A32). The 10 items of this dimension mention the students' satisfaction of being in the different dependencies of the university (Faculty, Career), in the value and achievement of the objectives of belonging to the institution and in the desire to continue the university studies or not. In this case, 4 items that originally belonged to the dimension of academic adjustment (A5: "I know why I am at the University and what I want to get out of it"; A58 "Most of the things that I'm interested in are not related to what I do in the Career"; A19 "My academic goals are well defined"; A32 "I doubt the value that a university degree can have") were included in this new dimension. The inverse items were: I47, I15, A5, A19.

And finally factor 4 corresponds to the dimension of academic adjustment (items: A54, A43, A36, A62, A50). These five items refer to the students' satisfaction regarding the quantity, variety and presentation of the academic activities of the subjects; as well as the professors who teach them. All these questions corresponded to the dimension of academic adjustment in the original version of the scale. After making the respective modifications, a new version of the SACQ with 38 reagents was available.

\section{Conclusions}

The objective of this work was to evaluate the internal structure of the SACQ in a sample of Chilean students. The responses of a total of 249 first-year students during the 2018-2019 academic year were analyzed. The analysis of the 4-factor model proposed in the original version [3] adapted to Spanish by [21] was carried out.

Based on the changes in the items in the dimensions of the SACQ in previous studies [26] and the authors' recommendations about the reconsideration of the allocation of items [27], an EFA was performed to assess the distribution of the items in the sample of Chilean first-year university students. Unlike what was found in previous studies [3, 21], all items belonging to the dimension of social adjustment presented loads only in that dimension. The behavior of the items of the academic dimension was different, which showed significant loads in other factors, being composed by 5 items only.

In the case of the personal-emotional adjustment dimension, three items from the academic adjustment dimension were included in this factor. These items refer to perceptions of the students' ability and motivation to face academic responsibilities. This finding highlights the consideration of items related to the perception of competence, motivation and coping as personal elements of the students rather than merely academic elements. Regarding the institutional dimension, three academic items conformed this factor.

It is concluded that the SACQ was made up of 38 items that represent 4 factors corresponding to: (1) personal-emotional items (P7, P20, P64, P11, A29, P28, P45, P2, P12, P40, P55, P38, A21, A41, P31), (2) social items (S63, S9, S4, S1, S37, S65, S18, S57), (3) institutional items (I60, I47, I59, I15, I34, A5, A58, I61, A19, A32) and (4) academic items (A54, A43, A36, A62, A50). It is recommended in future studies to carry out confirmatory factor analysis and other indices that allow evaluating psychometric properties.

\section{Acknowledgments}

This article ascribes to the research grant: "Explanatory model of academic adjustment and the intention of abandonment in university students" (In Spanish Modeloexplicativo del ajusteacadémico y la intención de abandonoen estudiantes universitarios) to opt to the degree of Doctor in Psychology at the University of Concepción, Chile. It is financed by CONICYT PFCHA National Doctorate Scholarships (In Spanish Becas de Doctorado Nacional CONICYT PFCHA) / Folio 21170795.

\section{REFERENCES}

[1] Salami SO. Psychosocial Predictors of Adjustment among First Year College of Education Students. Online Submission. 8[2]:239-248 (2011).

[2] Baker RW, Siryk B. Exploratory intervention with a scale measuring adjustment to college. Journal of counseling psychology. 33[1]:31-38 (1986).

[3] Baker RW, Siryk B. SACQ: Student adaptation to college questionnaire: Manual: Western Psychological Services (1989).

[4] Credé M, Niehorster S. Adjustment to college as measured by the student adaptation to college questionnaire: A quantitative review of its structure and relationships with correlates and consequences. Educational Psychology Review. 24[1]:133-165 (2012). 
[5] Aljohani O. A comprehensive review of the major studies and theoretical models of student retention in higher education. Higher Education Studies. 6[2]:1-18 (2016).

[6] Krotseng M. Predicting persistence from the student adaptation to college questionnaire: Early warning or siren song? Research in Higher Education. 33[1]:99-111 (1992).

[7] Páramo MF, Martínez Z, Tinajero C, Rodríguez MS. The impact of perceived social support in first-year Spanish collage students adjustment Educational Alternatives. 12[1]: 289-300 (2014).

[8] Bean J, Metzner BS. A conceptual model of nontraditional undergraduate student attrition. Review of educational research. 55[4]:485-540 (1985).

[9] Pascarella ET, Terenzini PT. Predicting freshman persistence and voluntary dropout decisions from a theoretical model. The journal of higher education. 51[1]:60-75 (1980).

[10] Tinto V. Dropout from higher education: A theoretical synthesis of recent research. Review of educational research. 45[1]:89-125 (1975).

[11] MINEDUC. Estadística de la Educación Superior. Recuperado de: http://datos.mineduc.cl/datasets/171898/pla nes-y-programas-de-estudios-2012/2012.

[12] SIES. Informe retención de 1er año de pregrado. Cohortes 2013 - 2017. División de Educación Superior, Ministerio de Educación. 2017; Recuperado en https://analisis.umag.cl/do cumentos/retencion_1er_ano_sies_2018.pdf.

[13] Páramo MF, Araújo AM, Tinajero-Vacas C, Almeida LS, Rodríguez-González MS. Predictors of students’ adjustment during the transition to university in Spain. Psicothema. 29[1]:67-72 (2017).

[14] Gómez E, Urzúa A, Glass CR. International student adjustment to college: Social networks, acculturation, and leisure. Journal of Park and Recreation Administration. 32[1]: 7-25 (2014).

[15] Borzone MA. Autoeficacia y vivencias académicas en estudiantes universitarias. Acta Colombiana de Psicología. 20[1]:266-274 (2017).

[16] Brady - Amoon P, Fuertes JN. Self - Efficacy, Self - Rated abilities, adjustment, and academic performance. Journal of Counseling \& Development. 89[4]:431-438 (2011).

[17] Chavoshi S, Wintre MG, Dentakos S, Wright L. A developmental sequence model to university adjustment of international undergraduate students. Journal of International Students. 7[3]:703-727 (2017).

[18] Páramo F, Tinajero C, Rodriguez S. Levels of adjustment to college, gender and academic achievement in first-year Spanish students. Education Applications Developments Advances in Education Educational Trends Series Edited by:
Mafalda Carmo. 34[1]:35-43 (2015).

[19] Rienties B, Beausaert S, Grohnert T, Niemantsverdriet S, Kommers P. Understanding academic performance of international students: the role of ethnicity, academic and social integration. Higher education. 63[6]:685-700 (2012).

[20] Horgan A, Sweeney J, Behan L, McCarthy G. Depressive symptoms, college adjustment and peer support among undergraduate nursing and midwifery students. Journal of Advanced Nursing. 72[12]:3081-3092 (2016).

[21] Rodríguez M, Tinajero C, Guisande A, Páramo MF. The student adaptation to College Questionnaire [SACQ] for use with Spanish students. Psychological Reports. 111[2]:624-640 (2012).

[22] Baker RW, Siryk B. Student adaptation to college questionnaire (SACQ). Los Angeles, CA: Western Psychological Services (1986).

[23] Beyers W, Goossens L. Concurrent and predictive validity of the Student Adaptation to College Questionnaire in a sample of European freshman students. Educational and Psychological Measurement 62[3]:527-538 (2002).

[24] Carayon S, Gilles PY. Développement du questionnaire d'adaptation des étudiants à l'université [QAEU]. L'orientationscolaire et professionnelle. 34[2]:165-189 (2005).

[25] Feldt RC, Graham M, Dew D. Measuring adjustment to college: Construct validity of the student adaptation to college questionnaire. Measurement and Evaluation in Counseling and Development. 44[2]:92-104 (2011).

[26] Roszkowski MJ. An Investigation of the Correctness of Item Assignment on the Subscales of the Student Adaptation to College Questionnaire and its Temporal Stability. Journal of College Student Retention: Research, Theory \& Practice.15[4]:463-488 (2014).

[27] Taylor MA, Pastor DA. A confirmatory factor analysis of the Student Adaptation to College Questionnaire. Educational and Psychological Measurement. 67[6]:102-118 (2007).

[28] Tao S, Dong Q, Pratt MW, Hunsberger B, Pancer SM. Social support: Relations to coping and adjustment during the transition to university in the People's Republic of China. Journal of Adolescent research.15[1]:123-144 (2000).

[29] Grama B. The Student Adaptation to College Questionnaire (SACQ) for Use With Romanian Students. Psihologia Resurselor Umane.16[1]:16-26 (2018).

[30] Montero I, León OG. A guide for naming research studies in Psychology. International Journal of clinical and Health psychology. 7[3]:847-862 (2007).

[31] Field A. Discovering statistics using IBM SPSS statistics: sage; (2013). 